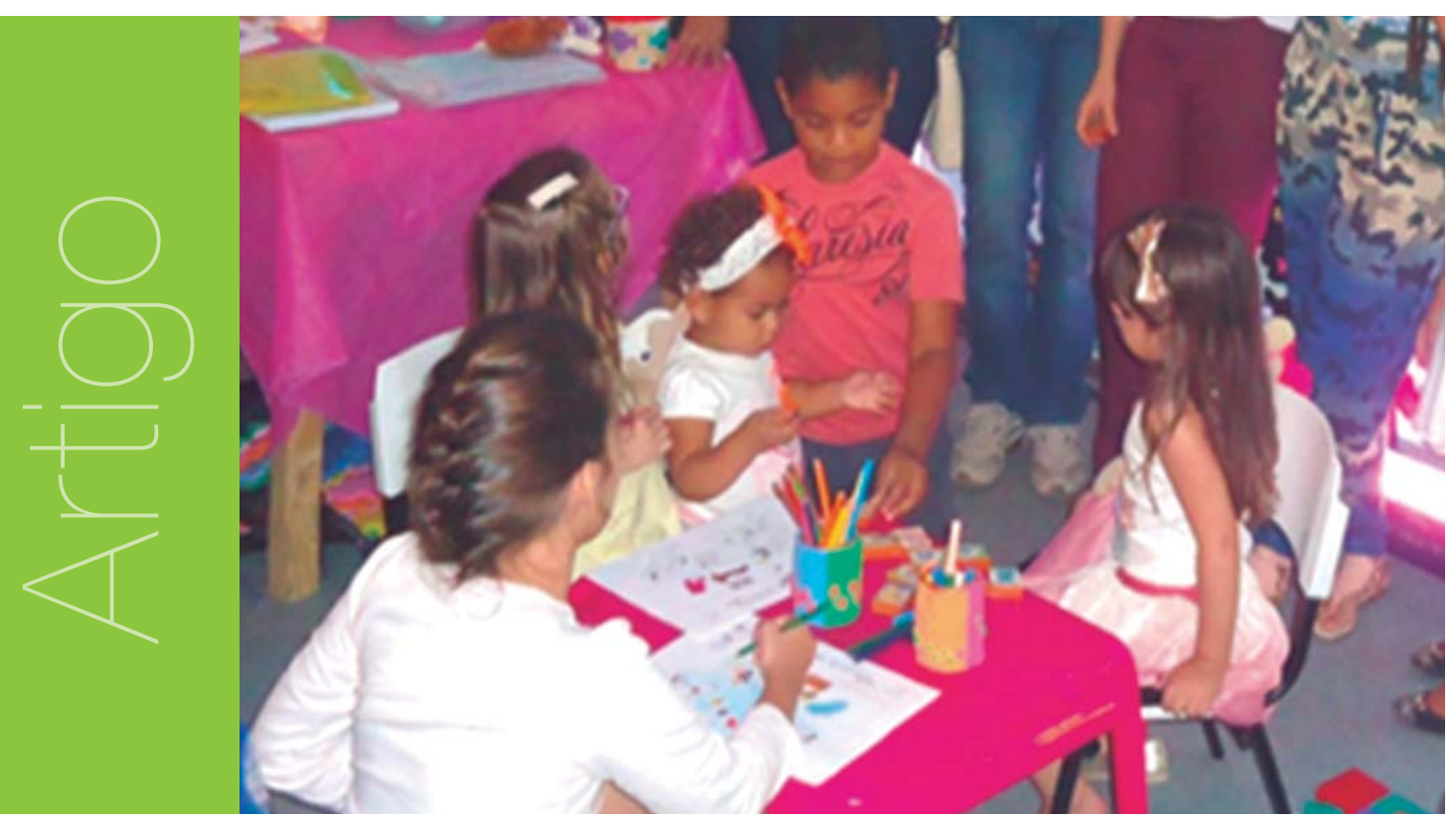

\title{
Educação Financeira Infantil: Brincando com dinheiro
}

\author{
Rosimery Alves de Almeida Lima1 - rosy.alves@bol.com.br \\ Ana Flávia Albuquerque Ventura² - ana.flavia@ufcg.edu.br \\ Raul Ventura Júnior ${ }^{3}$ - raul.ventura@ufcg.edu.br \\ Francisco José da Silva Junior ${ }^{4}$ - fjsilvajunior5@gmail.com
}

\section{RESUMO}

Este estudo analisa os resultados de uma ação extensionista desenvolvida em 2014, pela Universidade Federal de Campina Grande - Sousa/PB, objetivando-se disseminar a educação financeira às crianças do ensino fundamental do segundo ao quinto ano das escolas públicas e privadas da referida cidade. Para a realização desse trabalho, foram ministradas aulas e diversas atividades lúdicas sobre a temática proposta. Nessas aulas, empregou-se ficha de cadastramento e acompanhamento dos alunos, oficinas, feiras, teatro com fantoches e apresentações em slides e vídeos. Observou-se que o projeto diferencia-se pela proposta de formar cidadãos mais conscientes no uso dos recursos financeiros.

\section{PALAVRAS-CHAVE}

Finanças Pessoais. Alfabetização Financeira. Extensão Universitária. Recursos Financeiros.

\section{ABSTRACT}

This study analyzes the results of a extension action developed in 2014 , the Federal University of Campina Grande - Sousa / PB, aiming to disseminate financial education to elementary school

\footnotetext{
1 Graduanda no Bacharel em Administração pela Universidade Federal de Campina Grande;

2 Graduada em Ciências Contábeis pelo Centro Universitário de João Pessoa; Especialista em Controladoria e Contabilidade; Mestre em Contabilidade pelo programa da UnB/UFPB/UFRN e Professora na Universidade Federal de Campina Grande;

3 Graduado em Ciências Contábeis pelo Centro Universitário de João Pessoa; Especialista em Contabilidade e Auditoria Pública e Professor na Universidade Federal de Campina Grande;

4 Graduando no Bacharel em Ciências Contábeis pela Universidade Federal de Campina Grande;
} 
children from the second to the fifth year of public and private schools of that city. To perform this work, classes and various recreational activities on the proposed theme were given. In these classes, we used registration form and monitoring of students, questionnaires, workshops, theater with puppets and slides videos and presentations. It was observed that the project differs from the proposal to train more conscious citizens in the use of financial resources.

\section{KEYWORDS}

Personal Finance. Financial Literacy. University Extension. Financial Resources.

\section{Introdução}

Com o crescimento econômico do Brasil nos últimos anos, a oferta de crédito aumentou e, por conseguinte, observou-se um endividamento maior da população brasileira, que a partir de bens comprados com grandes prazos de financiamentos, ou que, na maioria das vezes, adicionados a cobrança de juros abusivos, compromete-se a maior parte da renda mensal.

Segundo o Instituto Brasileiro de Geografia e Estatística (IBGE, 2008; 2009) 85\% da população residente do país apresenta dificuldades na gestão das finanças pessoais. Assim na ótica de Frankenberg (1999) o endividamento do brasileiro relaciona-se diretamente com a ausência de uma educação financeira. Destarte, planejar e controlar a vida financeira pessoal pode ser uma tarefa imprescindível e, ao mesmo tempo, um desafio que muitos adultos não conseguem realizar com sucesso.

Neste contexto, percebe-se que se faz necessário iniciar a educação financeira desde cedo, pois, cada vez mais as crianças e adolescentes se encantam com o consumismo exagerado (PADRO, 2013). Para Serpa (2012), a intensa estratégia de marketing, voltada principalmente para crianças, incentiva a sociedade contemporânea para o consumismo. Moreira (2002) acrescenta que o dinheiro tem participação em todos os momentos da nossa vida e constitui como uma variável indispensável na realidade econômica e social, portanto, se faz necessário dar à devida importância a educação financeira.

Segundo o Instituto Data Popular (2008) em pesquisa realizada com público com faixa etária entre 13 a 15 anos e pertencentes à classe $\mathrm{C}$, revelou que a noção de dinheiro acontece aos cinco anos de idade, quando eles têm o primeiro contato com o dinheiro, por meio de gastos superficiais e pequenas doações dos pais. Entretanto D'Aquino (2008) explica que a educação financeira deve ser privilégio de crianças de todas as classes sociais.

Tendo em vista o exposto nesse estudo inferiu-se como questão problema: Como disseminar a educação financeira as crianças das Escolas Públicas e Privadas do Município de Sousa - PB?

Deste modo, para que esta resposta fosse obtida delineou-se como objetivo: disseminar a educação financeira as crianças do ensino fundamental do segundo ao quinto ano das Escolas Públicas e Privadas da Cidade de Sousa - PB, a partir de uma ação extensionista intitulada Educação Financeira Infantil: Brincando com dinheiro, da Universidade Federal de Campina Grande, Campus Sousa - PB, onde se incentivou ao uso consciente dos recursos financeiros.

\section{Fundamentação teórica}

\subsection{Educação infantil}

A educação financeira infantil desde os primórdios da humanidade era dada como incentivo e responsabilidade inicial por meio das famílias. Eram junto com outras crianças, pessoas e indivíduos de convivência geral ao qual se dava o desenvolvimento da educação das crianças (CRAIDY; KAERCHER, 2007). 
Na luz do entendimento de Pereira et al. (2009), a partir do surgimento da classe burguesa, tendo em vista o desenvolvimento dos comércios e cidades, passou-se a existir uma maior preocupação, vinda da assistência social, com as crianças. Entretanto, a Revolução da Burguesia introduziu a necessidade de se elaborar uma nova metodologia educacional. Alinhadas à nova ordem social, a burguesia se dedicou para expulsar a igreja dos seus últimos redutos (LIMA, 2009).

Observa-se que o impulso para o norteamento da educação infantil, visado pela burguesia, era apenas de proporcionar, por meio das crianças, a queda da igreja, que até então era soberana, proporcionando a sua classe um maior conhecimento e desenvolvimento. As crianças eram vistas como 0 futuro desde então, daí a lógica estratégica. Contudo, os benefícios para ambas foram logo visados, conseguindo não só a satisfação da classe como também um desenvolvimento infantil a princípio (PEREIRA et al., 2009). No entanto, a educação se afasta do empirismo e evolui para a pedagógica, se preocupando com as crianças da faixa etária do zero aos seis anos de idade. Colégios abrem acesso aos filhos de burgueses e classes baixas separadamente. Nesse contexto, a Igreja católica perde espaço no que diz respeito à educação. E assim inicialmente criaram-se três níveis de ensino, a priori para adequar o nível de conhecimento à estatura física e mental da criança, proporcionando um desenvolvimento intelectual correspondente à faixa etária (LIMA, 2009).

Atualmente no Brasil, as instituições de ensino se adequaram à formatação de níveis de escolaridade que permeia nove anos letivos para 0 ensino fundamental, três para 0 ensino médio e na educação superior pode variar dependendo do ramo profissional escolhido. Enfatizando o ensino infantil, além dos cinco primeiros níveis, há a existência do maternal, que seria uma iniciação ou incentivo à criança a se adaptar ao meio escolar e despertá-lo para a aprendizagem. Já que segundo a Lei de Diretrizes e Bases da Educação (Lei no 12.796, de 2013), a educação infantil, primeira etapa da educação básica, tem como finalidade o desenvolvimento integral da criança de até cinco anos, em seus aspectos físico, psicológico, intelectual e social, complementando a ação da família e da comunidade, por meio de creches para crianças até três anos e pré-escolas para crianças de quatro a cinco anos.

\subsection{Educação financeira}

A educação financeira, apesar de ser uma temática bastante discutida e evidenciada no Brasil, ainda é um assunto incipiente, pois, de acordo Instituto DSOP (Diagnosticar, Sonhar, Orçar e Poupar) de Educação Financeira, que se destina a disseminar a educação financeira no Brasil e no mundo, em média 200 escolas particulares apresentam no seu programa pedagógico a educação financeira. Para tanto, institui-se a Estratégia Nacional de Educação Financeira (ENEF), sob o decreto no 7.397, de 22 de dezembro de 2010, que busca promover a Educação Financeira e previdenciária por meio de ações voltadas especificamente para a inclusão nas escolas, além de atuações destinadas ao público-alvo adulto no fortalecimento da tomada de decisões conscientes dos consumidores.

Segundo Prado (2013) a educação financeira é uma ferramenta essencial para a redução da desigualdade social no Brasil, visto que, pode permitir uma sociedade mais consciente e sustentável no futuro. Todavia, na escola aprendem-se várias coisas formidáveis para nosso desenvolvimento cultural, profissional e social. Porém na maioria das vezes a Educação Financeira não é abordada, ficando em segundo plano. A educação financeira pode ampliar a compreensão do cidadão, para que seja capaz de fazer escolhas conscientes quanto à administração dos seus recursos financeiros e contribuir para a eficiência e solidez do país, oferecendo a base imprescindível para que as crianças se tornem adultos com bons hábitos, contribuindo para a formação de indivíduos e sociedades responsáveis e comprometidos com o futuro.

Frankenberg (1999) aponta que 0 ambiente e as pessoas que 0 envolvem serão decisivos nas escolhas de suas vidas. De tal modo, parte-se dessa visão que 0 ambiente e as pessoas que fazem parte do convivio de uma criança podem ser as principais formadoras do caráter da mesma no engajamento da aquisição e do aperfeiçoamento do conhecimento acerca desta educação. Nessa ótica, Zerrenner (2007) aduz que a educação financeira permite que 0 indivíduo mude suas preferências e administre seu comportamento de consumo, gerando economias. Para 
tanto, Stehling e Araújo (2008) acrescentam que esta educação deve ser priorizada e iniciada o mais cedo possível para que a criança adquira uma relação saudável com 0 dinheiro para conquistar a independência econômica e ter consciência na utilização dos recursos financeiros.

Contudo, a melhor utilização dos recursos perante necessidades e diferenciação das importâncias e urgências de curto prazo para as de longo caracterizam a consciência financeira. Saber utilizar seus recursos no momento certo e na hora certa é de extrema importância para evitar saldos desfavoráveis ou dívidas futuras.

\subsection{Educação financeira infantil}

D’Aquino (2008) frisa que a educação financeira infantil pode ser capaz de possibilitar às crianças o conhecimento de como ganhar dinheiro, de ser capaz de poupar e saber como gasta-lo de forma eficiente. Neste ínterim, a educação financeira ensina as crianças a perceberem as melhores escolhas sobre as finanças pessoais e as consequências destas escolhas para a vida. Também possibilita que adquiram condições de entenderem que tudo isso deve ser resguardado, sob a convicção de que todo ganho e todo uso do dinheiro deve ser regido pela mais rigorosa ética no meio social, estimulando um uso mais consciente do dinheiro a partir de pequenas ações e gestos realizados ainda na fase infantil, consequentemente regulada a fase adulta.

Deste modo, é louvável dizer que as boas práticas de leitura e escrita são relevantes em todos os momentos e nos mais variados aspectos da vida das pessoas, mas se ter a oportunidade de se adquirir este conhecimento quando ainda criança pode ser mais vantajoso e proveitoso que deixar para aprender na fase adulta, principalmente no que faz referencia à educação financeira (SOUZA, 2013).

Segundo Kassardjian (2013), a linguagem utilizada com as crianças deve estar de acordo com a faixa etária, pois, ao passar dos anos, muda-se o nível de compreensão e de abstração dos indivíduos. Dessa forma, não se deve, por exemplo, introduzir conceitos complexos para crianças pequenas ou até mesmo infantilizar a abordagem direcionada aos adolescentes, pois essa prática comprometeria a eficácia da educação financeira como processo, cujo objetivo primordial é estabelecer ensinamentos de longo prazo que farão com que as crianças e jovens se tornem adultos mais conscientes.

\section{Metodologia}

Gil (2002) aborda que a metodologia pode ser vista como processo sistemático que leva 0 pesquisador à abordagem da realidade e é 0 caminho através do qual os fenômenos se desenvolvem. No que tange aos procedimentos técnicos, caracterizar-se-á como pesquisaação, já que Baldissera (2001) assegura que esse tipo de pesquisa agrega diversas técnicas de pesquisa social, por meio da coleta, interpretação dos dados, intervenções na busca da solução de problemas, organizações e programações da ação coletiva na produção do conhecimento.

A população dessa pesquisa compreende as escolas do município de Sousa, adotando-se como critério inicial as escolas municipais da rede pública e privada localizadas no espaço urbano sousense, já que dada a limitação dos recursos financeiros tornaria inviável a expansão à zona rural. Em seguida, optou-se pelas que trabalhavam com o ensino fundamental do segundo ao quinto ano, de ambas as redes de ensino. Paralelamente a este critério, também se levou em conta se as referidas instituições não possuíam na grade curricular a educação financeira e se dispuseram a participar do projeto.

Após a definição desse conjunto de variáveis, de um universo de oito escolas públicas municipais e duas da rede privada que possuíam o respectivo perfil, selecionaram-se duas, uma de cada rede. Ressalta-se que trabalhar com um número maior de escolas, demandaria um período maior de horas diárias nas escolas, o que necessitaria de um número maior de extensionistas para poder cumprir o cronograma do projeto.

A Escola Pública Municipal A (nome fictício) está localizada próxima a um dos bairros mais carentes da cidade, Várzea da Cruz, e é mantida pela Prefeitura do Município. Atende crianças do 
segundo ao quinto ano do ensino fundamental e possui uma pequena estrutura física. As duas turmas existentes em cada horário (manhã/tarde) possuíam faixa etária diferentes, que variavam entre sete a 12 anos e em média, 30 alunos por sala. Em contrapartida, a Escola de Ensino Privado B (nome fictício) está localizada em um bairro de classe média alta e leciona da educação infantil ao ensino médio, com em torno de 40 alunos por série nos turnos da manhã e tarde.

Em seguida, apresentou-se a proposta à diretoria e toda a equipe de profissionais envolvidos diretamente com o processo pedagógico escolar. Definiu-se o cronograma dos trabalhos e os temas a serem abordados acerca da temática educação financeira de acordo com D’Aquino (2008) e Von et al., (2001). Por fim, iniciaram-se os encontros semanais com horários pré-definidos, com as professoras de cada série, evitando-se o choque com o cronograma pedagógico da escola.

Para o alcance do objetivo delineado, a definição e elaboração de todo conteúdo educativo variaram de acordo com a faixa etária dos alunos, apresentados em linguagem lúdica e interativa, por meio de aulas, apresentações, jogos, oficinas, teatros (Fig. 1), debates, atividades lúdicas e uma feira (Fig.2) como os produtos produzidos por eles próprios nas oficinas, realizada conjuntamente com os alunos de todas as séries de cada escola. Assim, iniciaram-se os encontros com cada série, duas vezes por semana em cada escola e com duração de uma hora cada encontro. As atividades nas escolas ocorreram durante os meses de junho a dezembro no ano de 2014.

Figura 1: Teatro com bonecos fantoches na Escola Privada B (Nome fictício), Sousa - PB.



Desse modo, avaliou-se através das atividades o conhecimento dos alunos acerca da educação financeira e de suas habilidades em lidar com o dinheiro, iniciando os trabalhos com os alunos do segundo ano, de ambas as escolas, com a apresentação da temática através da História do Dinheiro no Brasil e no Mundo (VON et a., 2001), por meio do teatro com bonecos fantoches (Fig. 1) para despertar a atenção das crianças. E em seguida, seguiu-se com a discussão entre a história e a vida real, explicando às crianças a importância do dinheiro e suas formas de administrá-lo. Posteriormente aos debates, realizaram-se atividades sobre os animais presentes nestas cédulas, a história de cada animal, e através de desenhos e escritas as crianças falaram sobre a compreensão do tema.

A História do Consumo Consciente e o Desenvolvimento Sustentável (VON et al.,2001) foi abordada no terceiro ano, através da com apresentações e atividades relacionadas à questão dos bens e/ou produtos. Sugerindo aos alunos que fizessem a seleção de produtos que desejariam ter e os que acreditariam que realmente precisariam ter, para que pudessem fazer um comparativo das mais diversas reações dos alunos e posteriormente debateu-se acerca disso. Nas oficinas as crianças montaram produtos domésticos a partir de materiais recicláveis 
e participaram de simulações de compras com uso das cédulas para colocarem em prática o conhecimento ora adquirido e estimularem a dinâmica de como ganhar dinheiro através de atividades relacionadas às práticas da reciclagem.

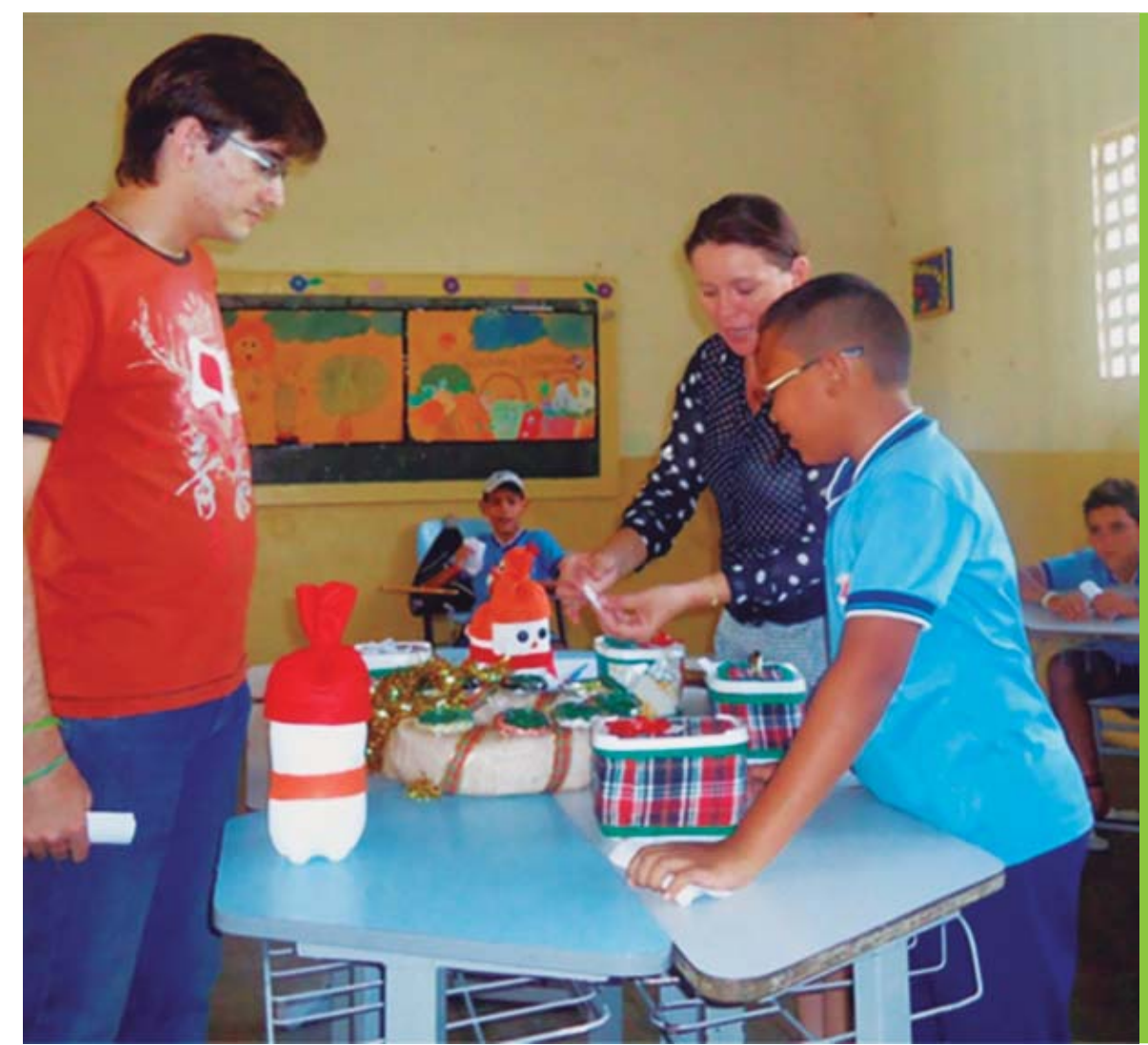

No quarto ano, apresentou-se a História da Mesada, Querer (versus) Precisar e Orçamento (VON et al.,2001), algumas definições e atividades acerca da temática, como exemplo planejamento financeiro. Participaram de gincanas e jogos sobre um Orçamento Doméstico, onde as crianças deveriam citar três despesas que a sua família tem todos os meses, consultando seus pais, e depois trazer para a sala de aula uma lista mais completa para debate sobre as prioridades dos gastos e melhor administração dos recursos financeiros.

A temática foi abordada no quinto ano, a partir da História dos Bancos, Cheques, Cartões e Investimentos (VON et al., 2001), intensificada com os debates, aulas e atividades sobre o papel do banco na sociedade e seus produtos, especificações sobre o uso dos cheques e cartões (débito e crédito) e simulações de compras com uso de todas as cédulas operantes no mercado, além das moedas e papel moeda, contribuindo-se para as crianças exercitarem as operações mentalmente e de forma prática e racional.

\section{Resultados e discussão}

Observou-se que o conhecimento acerca da educação financeira era limitado por parte dos alunos, que tampouco conheciam os benefícios que esta ferramenta poderia Ihes proporcionar. Assim, dentre as áreas abordadas pela educação financeira neste projeto, foram trabalhadas as suas quatro dimensões, "como ganhar dinheiro", "gastar", "poupar" e "doar" (D’Aquino, 2008), e enfatizado o "como gastar".

Assim, no intuito de testar o entendimento absorvido pelas orientações durante o projeto e analisar o comportamento das crianças para compras, considerando o poder de escolha, foi proposta uma feira (Fig. 2), no encerramento dos encontros em cada série, em ambas as escolas, com produtos feitos com material reciclado, produzidos por eles próprios nas
Figura 2: Alguns alunos simulando compras em uma feira realizada na Escola Pública Municipal A (Nome fictício), Sousa - PB.

Fonte: Dados desta pesquisa. 
oficinas, com a quantia de 187 reais, valor este que simboliza as cédulas de 2, 5, 10, 20, 50 e 100 reais, circulantes em nosso país.

Dos 233 participantes da feira nas escolas, 45\% eram meninas e 55\% meninos, distribuídos entre o segundo ao quinto ano fundamental em, $21,2 \%, 18,8 \%, 27,5 \%$ e $32,5 \%$, respectivamente, concentrando-se um número maior de alunos das turmas do quinto ano em ambas as escolas. Percebeu-se que um número significante de crianças despertou o interesse em lidar com o dinheiro, administraram melhor estes recursos, souberam realizar um orçamento financeiro, definiram prioridade de gastos, fizeram reservas financeiras e apresentaram mais consciência em relação ao consumismo exagerado e as compras por impulso, demonstrando assim a importância da educação financeira, onde os bons hábitos financeiros obtidos na infância são essenciais para toda nossa vida.

Assim, observou-se conforme exposto no Gráfico 1 que, em torno de 200 alunos participantes desta feira fizeram uma lista de compras para identificar as suas necessidades antes de realizarem 0 ato de compra em si. Em relação ao comportamento dos alunos, 186 fizeram a compra dos produtos necessários e ainda deixaram uma reserva financeira da quantia que the foi concedida. Dado à projeção do orçamento financeiro pessoal e as prioridades de gastos definidas pelos alunos, compreendeu-se que 184, ou seja, $79 \%$ das crianças fizeram as suas devidas anotações

Gráfico 1: Feira de Produtos nas Escolas Municipais da cidade de Sousa - PB.

Fonte: Elaborado pelos autores (2014)

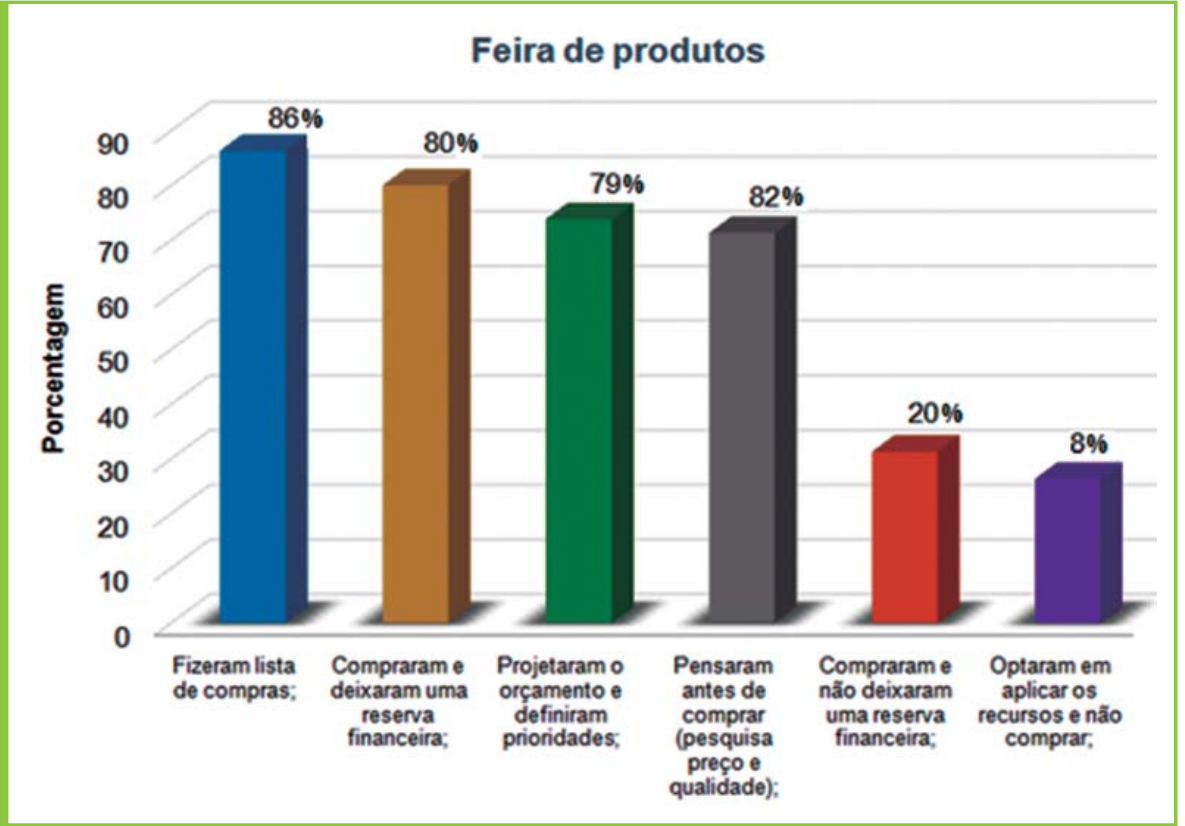

e definiram o quanto iriam gastar. Das 191 das crianças das escolas, o que equivale a $82 \%$ da amostra, conseguiram dentro os produtos ofertados escolher o melhor e que oferecia 0 menor preço, o que gerou uma economia nessa negociação. Analisou-se que 47 alunos usaram todos os seus recursos na compra dos produtos. Em contrapartida, 19 alunos não fizeram nenhum tipo de compra por achar desnecessária, optando pelo investimento dos seus recursos.

0 projeto também se expandiu na sociedade, destacando-se no evento Inova Sertão 2014 (Fig. 3), através do Espaço Kids com extensionistas em foco na Educação Financeira, atendendo a mais de 150 crianças nos dias do evento, disseminação o conhecimento acerca do tema, o que despertou o interesse de outras escolas e atores sociais em abordar a temática nos seus devidos espaços. Deste modo, durante a duração do projeto em torno de 240 alunos, do segundo ao quinto ano do Ensino Fundamental da Escola Pública e Privada da Cidade de Sousa - PB, foram beneficiados, além de um número bastante considerável de crianças que visitaram o Evento Inova Sertão 2014, nesta cidade. 


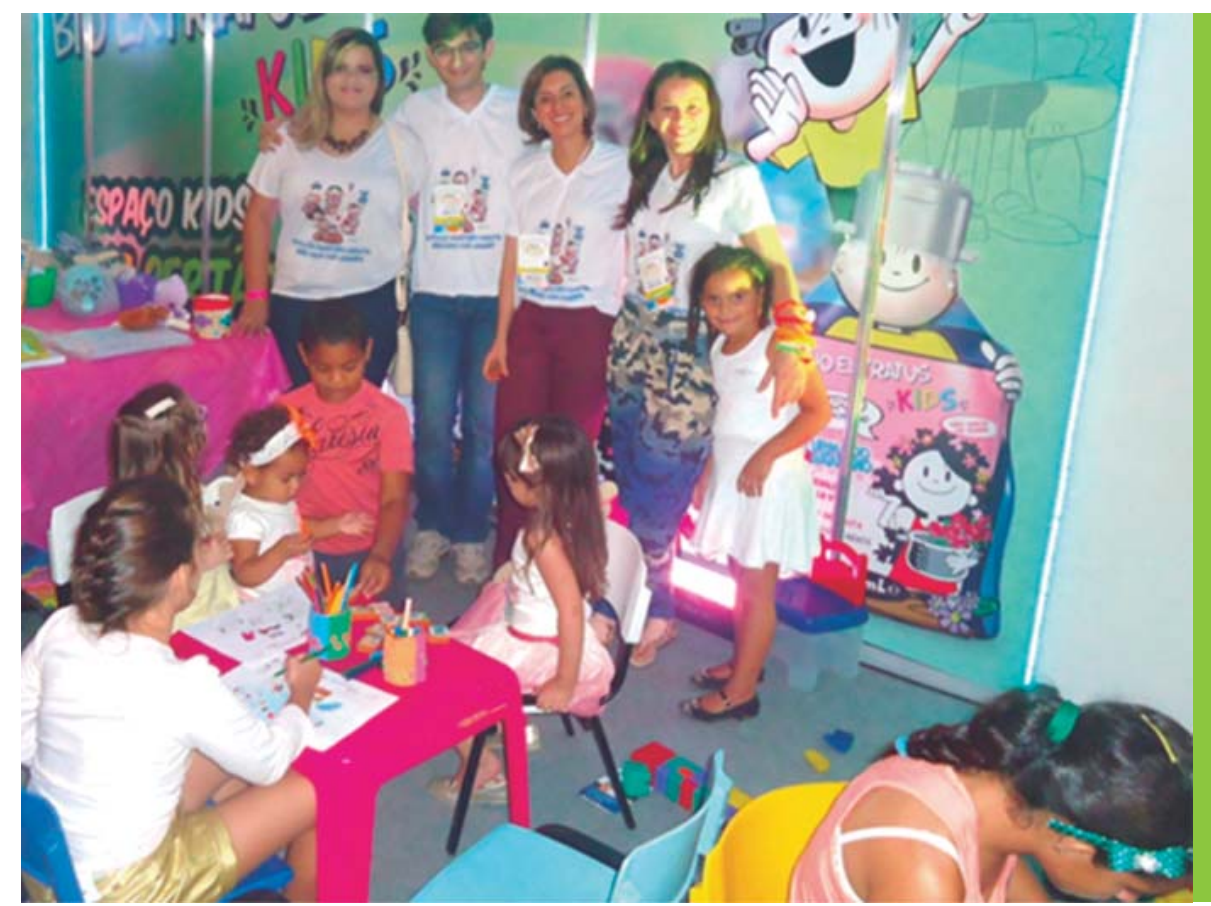

\section{Conclusões}

A educação financeira infantil é um processo sistemático que, realizado de maneira contínua, pode de fato estimular as crianças a terem comportamentos mais racionais e responsáveis. № entanto, existem em nosso país poucas escolas que contemplam a educação financeira em seu projeto pedagógico. Tendo em vista esta realidade, objetivou-se nesse estudo disseminar a educação financeira às crianças do ensino fundamental do segundo ao quinto ano das Escolas Públicas e Privadas da Cidade de Sousa - PB.

0 processo de educação financeira passa a ser um desafio global para os atores sociais, e deve ser visto também pelas escolas do nosso país como um tema transversal, já que se relaciona com várias disciplinas do sistema educacional e prepara as futuras gerações para desenvolver competências e habilidades imprescindíveis para lidar com decisões que poderão repercutir ao longo de suas vidas. Portanto, a Educação Financeira pode nos ajudar a ter melhor qualidade de vida, pois, as pessoas com melhor compreensão dos conceitos e produtos financeiros, com informações, entendimento e orientação clara, adquirem as capacidades necessárias para se tornarem conscientes das oportunidades e dos riscos financeiros.

Desse modo, foi através desta concepção que se enxergou a relevância deste estudo, tendo em vista a necessidade de propagar o conhecimento sobre esta temática, a partir do conhecimento e das boas práticas compartilhadas entre a escola, universidade e a sociedade em geral, contribuindo-se para que essas crianças preparem-se para superar os possíveis desafios impostos no dia a dia.

Enfim, esse projeto trouxe uma forma diferente de disseminar a educação financeira nas escolas da cidade de Sousa, propondo e incentivando as crianças a compreenderem melhor sobre a temática através das brincadeiras e atividades, ponderando diversos aspectos e avaliando possíveis impactos, permitindo a construção coletiva e cooperativa do conhecimento acerca da educação financeira.

Espera-se que, com este trabalho, mais escolas adotem a educação financeira como conteúdo pedagógico, favorecendo a construção do conhecimento consistente e o desenvolvimento de comportamentos sustentáveis na sociedade. E sugere-se a continuidade deste projeto como um número ainda maior de escolas para que mais pessoas possam se beneficiar com este conhecimento de tamanha importância para uma vida financeira saudável e melhor qualidade de vida no futuro.
Figura 3: Extensionistas disseminando a educação financeira no Espaço Kids do Evento Inova Sertão 2014, Sousa - PB.

Fonte: Elaborado pelos autores (2014) 


\section{Referências}

BALDISSERA, A. Pesquisa-ação: Uma metodologia do "conhecer" e do "agir" coletivo. Sociedade em Debate, Pelotas, v. 2, n. 7, p.5-25, 2001. Mensal.

BRASIL. Projeto de Lei da Câmara, $\mathbf{n}^{0} \mathbf{1 7 1}$ de 2009. BRASILIA, DF, 2009.

. Lei de Diretrizes e Bases da Educação, n⿳0 12.796 de 2013. BRASILIA, DF, 2013.

D'AQUINO, C. Educação Financeira: Como educar seu filho. Rio de Janeiro, Elsevier, 2008.

História do dinheiro. Disponível em: <http://www.monitorinvestimentos.com.br/ aprendizado.php?id_aprendizado=43>. Acesso em: 20 de Fev. de 2015.

CRAIDY, C. M. KAERCHER, G. E. P. S. da. Educação infantil: pra que te quero? - Porto Alegre: Artmed, 2001.

DATA POPULAR. A Educação Financeira no Brasil: relatório quali-quanti. 2008.

DSOP. Educação Financeira no Brasil e no mundo. Disponível em: <http://www.dsop.com. br/>. Acesso em: 21 de Jan. de 2015.

FRANKENBERG, L. Seu futuro financeiro. 16 ed. Rio de Janeiro: Campus, 1999.

GIL, A. C. Como elaborar projetos de pesquisa. 4 ed. São Paulo: Atlas, 2002.

IBGE. Instituto Brasileiro de Geografia e Estatística. Pesquisa de orçamentos familiares 2008-2009: despesas, rendimentos e condições de vida. Rio de Janeiro: 2010, 215 p. Disponível em: <http://www.ibge.gov.br/home/estatistica/populacao/condicaodevida/pof/2008_2009/ POFpublicacao.pdf >. Acesso em: 14 de Dez. de 2014.

KASSARDJIAN, A. C. C. Educação Financeira Infantil: como o incentivo a essa prática pode auxiliar na formação de adultos financeiramente mais conscientes. 2013. $93 \mathrm{f}$. Dissertação (Mestrado). Curso de Administração, Fundação Getulio Vargas, São Paulo, 2013.

LIMA, S. V. de. Educação infantil no mundo. Disponível em :<http://www.artigonal.com/ educacao-infantil-artigos/a-educacao-infantil-no-mundo-942990.html>. Acesso em: 25 de Març. 2015.

MOREIRA, A. S. Dinheiro no Brasil: um estudo comparativo do significado do dinheiro entre as regiões geográficas brasileiras. In: Estudos de Psicologia, Universidade Federal do Pará. 2002.

PEREIRA, D. H. et al. A educação financeira infantil e seu impacto no consumo consciente. 2009. 75 f. Monografia ( Bacharel em Administração) - Faculdades Integradas Campos Salles, São Paulo, 2009.

PRADO, R. S. de. Educação Financeira no ensino fundamental I. Dissertação - 2013.

SERPA, M. A. Educação Financeira: Crianças aprendem o valor do dinheiro e a importância do consumo consciente. Revista do Professor, Sao Paulo, v. 28, n. 111, p.14-17, 2012. Trimestral.

SOUZA, D. P. de. A importância da educação financeira infantil. 2013. 76 f. Dissertação (Mestrado) - Curso de Ciências Contábeis, Centro Universitário Newton Paiva, Belo Horizonte, 2013.

STEHLING, P.; ARAÚJO, M. Alfabetização Financeira. Revista da Escola Adventista, São Paulo, 2008.

VON, C. et al. Cartilha de Educação Financeira. São Paulo: Brincando na Rede, 2001. 48 p.

ZERRENNER, S. A. Estudo sobre as razões para a população de baixa renda. 2007. Dissertação. Universidade de São Paulo, São Paulo, 2007. 